\title{
MUDAS DE TOMATEIRO PRODUZIDAS À BASE DE PÓ DE COCO E ESTERCO BOVINO CURTIDO
}

Mateus Carvalho de Oliveira ${ }^{1}$, Júlio Renovato dos Santos², Diogo Francisco da Costa ${ }^{3}$, Gean Ribeiro da Costa ${ }^{4}$, Everton de Jesus Lourenço ${ }^{5}$

\begin{abstract}
RESUMO - O presente trabalho objetivou avaliar o potencial do pó de coco (PC) enquanto substrato e seus diferentes níveis de proporções juntamente com o esterco bovino curtido (EBC) na produção de mudas de tomateiro. O experimento foi conduzido em ambiente protegido com tela nylon (50\% luminosidade) na Secretaria Municipal de Agricultura do município de Coronel João Sá - BA, no período que compreende de maio a junho de 2018. Foram testados cinco tratamentos: T1 (100\% PC + 0\% EBC), T2 (90\% PC + 10\% EBC), T3 (80\% PC + $20 \%$ EBC), T4 (70\% PC + 30\% de EBC) e T5 (60\% PC + 40\% EBC), em delineamento inteiramente casualizado, com quatro repetições. Aos 24 dias após a semeadura avaliou-se a percentagem de germinação (PG), número de folhas definitivas (NFD), diâmetro do caule (DC), altura de plantas (AP), sistema radicular (SR), massa fresca da parte aérea (MFPA), massa fresca do sistema radicular (MFSR), peso matéria seca da parte aérea (PMSPA), peso da matéria seca da parte radicular (PMSPR) e o Índice de Qualidade de Dickson (IQD). Os dados obtidos foram submetidos à comparação entre médias e análise de variância a 5\% de probabilidade utilizando-se o software SISVAR. Todos os tratamentos analisados diferiram estatisticamente entre si, com exceção para a variável PG. O tratamento T1 promoveu um maior sistema radicular. Os níveis de esterco bovino curtido superiores a 30\% em pó de coco foram prejudiciais ao DC, MFSR, PMSPR, PMSPR e PMSPA. Os tratamentos onde si foi adicionado 10, 20 e 30\% de esterco bovino curtido em pó de coco promoveram maior qualidade das mudas de tomateiro.
\end{abstract}

Palavras chave: Fitotecnia, Lycopersicon esculentum L., produção, semiárido, substrato.

\section{TOMATO SEEDLINGS PRODUCED FROM COCONUT POWDER AND TANNED CATTLE MANURE}

\begin{abstract}
The present work aimed to evaluate the potential of coconut powder (PC) as substrate and its different levels of proportions together with tanned manure (EBC) in tomato seedling production. The experiment was conducted in a nylon screened environment (50\% luminosity) at the Municipal Secretary of Agriculture of Coronel João Sá - BA, from May to June 2018. Five treatments were tested: T1 (100\% PC+ $0 \% E B C), T 2(90 \% P C+10 \% E B C), T 3(80 \% P C+20 \% E B C), T 4(70 \% P C+30 \% E B C)$ and $T 5(60 \%$ PC $+40 \%$ EBC), in a completely randomized design with four replications. At 24 days after sowing, germination percentage (PG), number of definitive leaves (NFD), stem diameter (DC), plant height (AP), root system (SR), fresh shoot mass were evaluated. (MFPA), root system fresh mass (MFSR), area dry matter weight (PMSPA), root dry matter weight (PMSPR) and the Dickson Quality Index (IQD). The obtained data were submitted to the comparison between means and analysis of variance at $5 \%$ of probability using the SISVAR software. All treatments analyzed differed statistically, except for the variable PG. T1 treatment promoted a larger root system. Tanned manure levels above $30 \%$ in coconut powder were detrimental to DC, MFSR,
\end{abstract}

\footnotetext{
${ }^{1}$ Graduando do curso de Engenharia Agronômica da Faculdade do Nordeste da Bahia - FANEB. E-mail: mateuscarvalhooliveira0@gmail.com.

2 Engenheiro Agrônomo, mestre, professor do curso de Engenharia Agronômica da Faculdade do Nordeste da Bahia - FANEB. E-mail: jrsagronomo@yahoo.com.br.

${ }^{3}$ Graduando do curso de Engenharia Agronômica da Faculdade do Nordeste da Bahia - FANEB. E-mail: diogofrancosta@zipmail.com.br.

${ }^{4}$ Graduando do curso de Engenharia Agronômica da Faculdade do Nordeste da Bahia - FANEB. E-mail: gean_ribeirocosta@hotmail.com.

${ }^{5}$ Graduando do curso de Engenharia Agronômica da Faculdade do Nordeste da Bahia - FANEB. E-mail: evertonl272@gmail.com.
} 
PMSPR, PMSPR and PMSPA. The treatments in which 10, 20 and 30\% of coconut powder tanned manure were added promoted higher quality of tomato seedlings.

Keywords: Lycopersicon esculentum L., plant breeding, production, semi-arid, substrate.

\section{INTRODUÇÃO}

O tomateiro (Lycopersicon esculentum L.) apresenta-se como fonte importante de vitaminas com enorme utilização entre pequenos e médios agricultores (Andrade et al., 2017). Em 2017, sua produção mundial foi de 182.301,395 toneladas, apresentando crescimento médio anual de 3\% nos últimos dez anos e se destacando entre as hortaliças mais consumidas do mundo (FAOSTAT, 2017).

No Brasil, considerando os aspectos socioeconômicos relativos à demanda de consumo, geração de emprego e renda, além da participação expressiva no agronegócio o tomateiro é a hortaliça mais importante (Brito Junior, 2012), sendo a mais produzida e consumida (Trani et al., 2015; Canella et al., 2018). O país teve uma produção de 4.373 .047 toneladas, sendo o estado da Bahia o terceiro maior produtor em âmbito nacional e primeiro em escala regional com $43 \%$ de toda produção nordestina (Instituto Brasileiro de Geografia e Estatística - IBGE, 2017).

$\mathrm{Na}$ cultura do tomateiro, assim como, para a maioria das hortaliças, o método de propagação por mudas é o mais indicado (Costa et al., 2017). Desta forma, caso o produtor queira produzir suas próprias mudas, este terá que adquirir substratos presentes no mercado, devendo avaliar para quais espécies de hortaliça estes são mais adequados (Souza et al., 2007). Há assim, a necessidade de se verificar experimentalmente, para cada espécie vegetal, o tipo de substrato ou a melhor mistura de substratos que permita a obtenção de mudas vigorosas e que disponham de uma maior qualidade (Costa et al., 2009).

Neste contexto, e tendo em vista que o substrato pó de coco vem se destacando com ampla utilização para produção de mudas hortícolas. O objetivo deste trabalho foi avaliar o potencial do pó de coco enquanto substrato e seus diferentes níveis de proporções juntamente com o esterco bovino curtido que fossem mais adequados na produção de mudas de tomateiro.

\section{MATERIAIS E MÉTODOS}

O trabalho foi conduzido em ambiente protegido com sombrite de nylon, que promoveu redução de $50 \%$ da incidência luminosa sobre as mudas, localizado nas coordenadas $10^{\circ} 17^{\prime} 02^{\prime \prime} \mathrm{S}$ e $37^{\circ} 55^{\prime} 33^{\prime \prime}$ W, e $251 \mathrm{~m}$ de altitude, no período que compreende de maio a junho de 2018. O clima da região enquadra-se como sendo do tipo $\mathrm{BSh}$, seco e de estepe quente, segundo classificação de Köppen, com temperaturas médias anuais superiores a $18^{\circ} \mathrm{C}$ e precipitações pluviométricas inferiores a $1000 \mathrm{~mm}$ (SÁ JÚNIOR, 2009).

O delineamento experimental utilizado foi $\mathrm{O}$ inteiramente casualizado (DIC) com cinco tratamentos (T1, T2, T3, T4 e T5) e quatro repetições, sendo cada parcela constituída de 16 células semeadas de onde retirou-se ao final 8 plantas úteis. Para o ensaio experimental foram utilizados cinco tipos de combinações de pó de coco e esterco bovino curtido: T1 (100\% de pó de coco $+0 \%$ de esterco bovino curtido), T2 (90\% de pó de coco $+10 \%$ de esterco bovino curtido), T3 (80\% de pó de coco $+20 \%$ de esterco bovino curtido), T4 (70\% de pó de coco $+30 \%$ de esterco bovino curtido) e T5 (60\% de pó de coco $+40 \%$ de esterco bovino curtido), sendo o tratamento $\mathrm{T} 1$, o tratamento testemunha. O material pó de coco foi adquirido em loja comercial, sendo lavado e posto a secar em exposição ao ambiente natural antes de sua utilização visando à retirada de substâncias residuais que outrora pudessem interferir em processos germinativos e desenvolvimento das plântulas. Enquanto que o esterco bovino curtido passou por um período fermentativo de 30 dias, tornando-o apto a utilização.

Para a implantação do experimento foi utilizado a variedade de tomateiro Santa Cruz Kada (Paulista), adquirida em estabelecimento comercial local. A semeadura foi efetuada após acondicionamento do substrato em bandejas de polietileno com 128 células e posterior perfuração com o auxílio de um furador manual na profundidade de $1 \mathrm{~cm}$, sendo semeadas três sementes em cada célula. O desbaste foi realizado aos dez dias após a semeadura, deixando-se uma plântula por célula (Silveira et al., 2002). O processo de irrigação foi realizado por meio de regador manual, duas vezes ao dia, durante toda a fase experimental, objetivando manter o substrato em sua capacidade de campo.

As avaliações foram feitas aos 24 dias após a semeadura (DAS), quando as mudas apresentaram de 4-6 folhas definitivas (Silva et al., 2012). Como parâmetros para análise de variáveis contabilizou-se a percentagem de germinação (PG), o número de folhas definitivas (NFD), 
desprezando-se as folhas menores que $1,5 \mathrm{~cm}$, diâmetro do caule (DC), diâmetro do caule mensurado com o uso de paquímetro manual de precisão em milímetros. Em seguida, as plantas foram lavadas para remoção do substrato aderido à raiz e mediu-se a altura de plantas (AP), tomando-se por base para medição o ponto onde se encontra o coleto até o ápice da parte aérea, comprimento do sistema radicular (CSR), mensurado desde a base do coleto até o ápice da raiz, sendo as duas variáveis determinadas em centímetros $(\mathrm{cm})$ com o auxílio de uma régua milimétrica, massa fresca da parte aérea (MFPA), massa fresca do sistema radicular (MFSR), peso matéria seca da parte aérea (PMSPA). Os valores referentes à massa fresca da parte aérea e a massa fresca do sistema radicular foram verificadas em gramas $(\mathrm{g})$, por meio de balança de precisão analítica $(0,01 \mathrm{~g})$, peso matéria seca da parte radicular (PMSPR) e o Índice de Qualidade de Dickson (IQD). E, por último, o material vegetal foi acondicionado em sacos de papel e secos em estufa de circulação forçada de ar a $65^{\circ} \mathrm{C}$, por 72 horas até atingirem peso constante, para determinação de massa seca (Spiassi et al., 2009; Borges et al., 2011, Barbosa et al., 2015).

Sendo o número final de plântulas normais emergidas transformado em porcentagem e considerado percentagem de germinação (PG) (Eicholz et al., 2012). O cálculo utilizado foi realizado conforme equação proposta por Laboriau e Valadares (1976, apud Demontiêzo et al., 2016): $\% \mathrm{E}=(\mathrm{N} / \mathrm{A}) \mathrm{X} 100$; em que: $\% \mathrm{E}$ - Percentagem de emergência; N- Número total de sementes emergidas e A Número total de sementes plantadas.

Após secagem do material, ocorreu a determinação dos valores referentes ao peso de matéria seca da parte aérea (PMSPA) e peso de mateira seca da parte radicular (PMSPR), ambos em gramas, sendo utilizada balança com (0,01g) de precisão. Segundo metodologia desenvolvida por Dickson et al. (1960) foi realizada a determinação do índice de qualidade das mudas de tomateiro, conforme a equação 1:

$\mathrm{IQD}=(\mathrm{PMSTotal}) /[(\mathrm{AP} / \mathrm{DC})+(\mathrm{PMSPA} / \mathrm{PMSR})] \quad($ Equação 1) em que, IQD - Índice de Qualidade de Dickson; MST - Massa seca total (g); AP - Altura da planta (cm); DC Diâmetro do colo $(\mathrm{cm})$; PMSPA - Peso da massa seca da parte aérea (g); PMSRA - Peso da massa seca da raiz (g).

Os dados obtidos foram submetidos à análise de variância e a comparação entre médias realizada por meio do teste de Tukey Significant Difference (TSD) a $5 \%$ de probabilidade utilizando-se o software estatístico SISVAR ${ }^{\circledR}$ versão 5.6 (Ferreira, 2008).

\section{RESULTADOS E DISCUSSÃO}

Para a variável percentagem de germinação (Tabela 1) não houve resultados significativos entre os tratamentos. Isso demonstra que o pó de coco juntamente com esterco bovino não proporcionou características que influenciaram negativamente a taxa de germinação das sementes de tomateiro para os níveis de concentração de esterco bovino utilizados. Olaria et al. (2016) ao trabalharem com diferentes tipos de substratos à base de turfa, casca de coco e vermicomposto no desenvolvimento de plântulas de espécies tradicionais de Solanaceae (tomate, pimentão e berinjela), também não encontraram diferença para esta mesma variável. Pacheco et al. (2006) afirmaram que substratos a base de pó de coco são leves, fáceis de manusear e possuem boa capacidade absortiva de água, não exigindo o reumedecimento diário e proporcionando um bom desempenho germinativo das sementes.

Tabela 1 - Percentagem de germinação (PG), diâmetro do caule (DC), altura de planta (AP) e número de folhas definitivas (NFD) de mudas tomateiro variedade Santa Cruz Kada (Paulista) em combinações de substrato de pó de coco e esterco bovino curtido. Coronel João Sá- BA, 2018

\begin{tabular}{|c|c|c|c|c|}
\hline Tratamentos & PG (\%) & $\begin{array}{c}\mathrm{DC} \\
(\mathrm{mm})\end{array}$ & $\mathrm{AP}(\mathrm{cm})$ & NFD \\
\hline $\begin{array}{c}\mathrm{T} 1 \text { (100\%PC + } \\
0 \% \mathrm{EBC})\end{array}$ & $\begin{array}{c}81,2500 \\
a\end{array}$ & $2,1165 \mathrm{~b}$ & 8,7775 b & $2,7338 \mathrm{c}$ \\
\hline $\begin{array}{c}\mathrm{T} 2 \text { (90\%PC + } \\
10 \% \mathrm{EBC})\end{array}$ & $\begin{array}{c}84,3750 \\
a\end{array}$ & $\begin{array}{c}2,2353 \\
a b\end{array}$ & $\begin{array}{c}11,1790 \\
\mathrm{a}\end{array}$ & $3,5550 \mathrm{~b}$ \\
\hline $\begin{array}{c}\text { T3 (80\%PC + } \\
20 \% \text { EBC) }\end{array}$ & $\begin{array}{c}86,9793 \\
a\end{array}$ & 2,4413 a & $\begin{array}{c}11,1140 \\
\mathrm{a}\end{array}$ & $4,3050 \mathrm{a}$ \\
\hline $\begin{array}{c}\mathrm{T} 4 \text { (70\%PC + } \\
30 \% \mathrm{EBC})\end{array}$ & $\begin{array}{c}81,7708 \\
\text { a }\end{array}$ & 2,4778 a & $\begin{array}{c}11,5865 \\
\mathrm{a}\end{array}$ & $4,2695 \mathrm{a}$ \\
\hline $\begin{array}{c}\mathrm{T} 5 \text { (60\%PC + } \\
40 \% \mathrm{EBC})\end{array}$ & $\begin{array}{c}84,3753 \\
a\end{array}$ & $2,1325 \mathrm{~b}$ & $\begin{array}{c}10,9653 \\
\mathrm{a}\end{array}$ & $\begin{array}{c}3,9763 \\
\mathrm{ab}\end{array}$ \\
\hline $\mathrm{CV} \%$ & 10,36 & 5,26 & 8,80 & 5,86 \\
\hline
\end{tabular}

*Médias seguidas de mesma letra, na coluna, não diferem entre si a 5\% da probabilidade pelo teste Tukey. $\mathrm{PC}=$ Pó de coco; $\mathrm{EBC}=$ Esterco bovino curtido.

De acordo com Lin; Luther e Hanson (2015), dependendo do custo da semente e da taxa de germinação, para se garantir abundância de mudas suficientes e que estejam prontas para o transplantio no momento ideal, o produtor pode semear de 15 a $100 \%$ de sementes adicionais na cultura do tomateiro. Desta forma, a utilização de pó de coco pode ser uma alternativa bastante viável para redução 
de gastos com a aquisição e perdas resultantes da não germinação de sementes do tomateiro, tendo em vista, que todos os tratamentos atingiram taxas de germinação acima de $80 \%$.

Agostinho (2014), concluiu que alguns substratos comerciais que continham pó de coco em sua composição não interferiram na porcentagem de germinação das sementes, o que também ocorreu neste trabalho. Rodrigues et al. (2013) avaliando substratos alternativos na germinação de sementes de manjericão, ao utilizar o substrato pó de coco, atingiu índices de percentagem germinativa bastante expressivos em torno de $95.71 \%$. Além disso, Nadai et al. (2015) descrevem que o substrato fibra de coco possibilita maior germinação das sementes de tomateiro o que corrobora as boas taxas de germinação encontradas neste trabalho.

Os tratamentos T3 e T4 apresentaram os maiores resultados para o diâmetro do caule (Tabela 1) com relação aos demais tratamentos apresentando valores médios de 2,44 e 2,47, respectivamente, embora estes não tenham diferindo do substrato T2 com valor médio de 2,23. Os tratamentos T1 e T5 apresentaram os menores diâmetro do caule. Tal fato pode estar associado às baixas concentrações de nutrientes em T1 que podem ter provocado um menor desenvolvimento da parte aérea das plantas de tomateiro, enquanto que o tratamento T5 em virtude de uma menor aeração provocada pelo decréscimo na concentração dos índices de pó de coco diminuiu o sistema radicular e aéreo da planta. Segundo Silva e Resck (1997) em algumas situações a alta relação $\mathrm{C} / \mathrm{N}$ dos materiais podem acometer reduções na disponibilidade do nutriente nitrogênio, deste modo, inibindo o crescimento das plantas e fazendo necessário o uso de adubação nitrogenada.

Segundo Daniel et al. (1997), o parâmetro diâmetro do caule, é o mais observado para indicar a capacidade de sobrevivência da muda no campo. Uma vez que, um maior diâmetro de caule está associado ao desenvolvimento mais acentuado da parte aérea e, em especial, do sistema radicular das plantas (Santos et al., 2016). Desta forma, a produção de mudas com maior diâmetro do caule acaba se traduzindo em ganhos, comportando-se como indicativo de mudas mais vigorosas (Pezzutti; Caldato, 2011; Santos et al., 2010). Além disso, influenciando sobre a ocorrência de um maior ou menor peso do fruto (Coelho et al., 2018).

Para variável altura das plantas o tratamento T1 obteve o menor resultado, sendo que os demais tratamentos apresentaram as maiores médias não diferindo estatisticamente entre si. Tal fato pode estar correlacionado devido o pó de coco conter uma baixa condutividade elétrica, apresentando baixo teor de nutrientes e sais totais dissolvidos (Pragana, 1999) e assim, fazendo-se necessário à sua combinação com outros materiais (Ramos et al., 2012).

Quanto ao parâmetro altura da planta (Tabela 1), este se mostra de grande valia apresentando boa contribuição relativa, sendo de fácil determinação e não destrutivo (Gomes et al., 2002).

O número de folhas (Tabela 1) de tomateiro mostrou-se significativo sendo que os tratamentos T3, T4 e T5 apresentaram os maiores resultados com número de folhas de $(4,30),(4,26)$ e $(3,97)$, respectivamente, não diferindo estatisticamente entre si. O valor médio do tratamento testemunha com $100 \%$ pó de coco apresentou os piores resultados e menores quantidades de folhas com média de (2,7338). Desta forma, demonstrando que a adição do material orgânico esterco bovino curtido até os níveis de $40 \%$, promoveu aumento do número de folhas na cultura do tomateiro. Nunes et al. (2012), também notaram que a adição de matéria orgânica proveniente de esterco de galinha em conjunto com diferentes níveis de pó de coco também resultou em variações no número de folhas definitivas da cultura do tomateiro até os níveis de $30 \%$.

A variável comprimento do sistema radicular (Tabela 2) mostrou-se significativa, com destaque para o tratamento T1 com $100 \%$ pó de coco $(11,62)$, sendo que os demais substratos (T2, T3, T4 e T5), tiveram valores inferiores não diferindo estatisticamente entre si. Tal fato pode estar atrelado aos componentes e misturas de substratos a base de fibra de coco possuírem como característica física alta porosidade (Ristow et al., 2010) e assim, promoveram aeração, retenção de umidade e excelente capacidade de estimular o enraizamento, enquanto substrato (Nunes, 2000). Contudo, tal tratamento não atingiu níveis estruturais equilibrados entre desenvolvimento radicular e parte aérea uma vez que possuiu o maior sistema radicular e os menores valores para altura de planta, diâmetro do caule, número de folhas definitivas e peso matéria seca da parte aérea.

Para o T1, o seu resultado pode ser relacionado à redução de nutrientes do substrato, consequentemente, estimulando o crescimento das raízes em busca de melhor aporte nutricional (Santos et al., 2015; Silva et al., 2014; Silva et al., 2018). E, uma vez que, o crescimento das raízes requerer uma maior quantidade de energia, a qual é desviada dos tecidos fotossintéticos das plantas, tem-se um menor acúmulo de biomassa em sua parte área (Verslues et al., 2006). Confirmando isso, Duarte e Peil (2010) afirmam em seu trabalho que os fotoassimilados têm a capacidade de serem translocados por meio de um sistema fonte-dreno das 
partes vegetativas de plantas para outros tipos de órgãos, entre estes, à raiz.

Tabela 2 - Comprimento do sistema radicular (CSR), massa fresca parte aérea (MFPA), matéria fresca do sistema radicular (MFSR) e peso matéria seca da parte radicular (PMSPR) de mudas tomateiro variedade Santa Cruz Kada (Paulista) em combinações de substrato de pó de coco e esterco bovino curtido. Coronel João Sá-BA, 2018

\begin{tabular}{|c|c|c|c|c|}
\hline Tratamentos & $\begin{array}{l}\text { CSR } \\
(\mathrm{cm})\end{array}$ & MFPA (g) & MFSR (g) & $\begin{array}{l}\text { PMS- } \\
\text { PR (g) }\end{array}$ \\
\hline $\begin{array}{c}\mathrm{T} 1(100 \% \mathrm{PC})+ \\
0 \% \mathrm{EBC}\end{array}$ & 11,6203 a & $0,4895 \mathrm{~d}$ & 0,0613 bc & $\begin{array}{l}0,0070 \\
\quad \text { cd }\end{array}$ \\
\hline $\begin{array}{c}\mathrm{T} 2(90 \% \mathrm{PC}+ \\
10 \% \mathrm{EBC})\end{array}$ & $9,0940 \mathrm{~b}$ & 0,8648 с & 0,1131 a & $\begin{array}{c}0,0103 \\
\text { ab }\end{array}$ \\
\hline $\begin{array}{c}\text { T3 (80\%PC + } \\
20 \% \mathrm{EBC})\end{array}$ & 9,1963 b & 0,9370 bc & $0,0929 \mathrm{ab}$ & $\begin{array}{c}0,0118 \\
\mathrm{a}\end{array}$ \\
\hline $\begin{array}{c}\mathrm{T} 4 \text { (70\%PC + } \\
30 \% \mathrm{EBC})\end{array}$ & 7,8095 b & 1,0835 a & $0,0863 \mathrm{abc}$ & $\begin{array}{c}0,0085 \\
\text { bc }\end{array}$ \\
\hline $\begin{array}{c}\mathrm{T} 5 \text { (60\%PC + } \\
40 \% \mathrm{EBC})\end{array}$ & 7,5003 b & $1,0250 a b$ & 0,0538 c & $\begin{array}{c}0,0050 \\
\mathrm{~d}\end{array}$ \\
\hline $\mathrm{CV} \%$ & 10,51 & 5,87 & 21,33 & 16,04 \\
\hline
\end{tabular}

*Médias seguidas de mesma letra, na coluna, não diferem entre si a 5\% da probabilidade pelo teste Tukey. $\mathrm{PC}=$ Pó de coco; $\mathrm{EBC}=$ Esterco bovino curtido.

Os tratamentos T4 e T5 atingiram os maiores valores de matéria fresca da parte aérea com $(1,08)$ e $(1,02)$, respectivamente (Tabela 2 ), não diferindo estatisticamente entre si, embora o tratamento T5 não tenha diferido estatisticamente do tratamento T3, com $(0,93)$. Além disso, nota-se que o aumento dos níveis de material orgânico provenientes do esterco bovino curtido até 30\%, em relação ao pó de coco, provocou aumentos na biomassa aérea da cultura do tomateiro. Os substratos T1 e T2 obtiveram os menores valores médios para variável MFPA, com $(0,48)$ e $(0,86)$, respectivamente. Tal fato pode ser explicado devido ao substrato composto somente por fibra de coco não possuir os nutrientes essenciais para as plantas, havendo a necessidade de fornecê-los de acordo com as exigências da espécie a ser cultivada, adicionando-se adubos ao substrato (Duarte et al., 2010).

Girotto et al. (2016) relatam que a adição de 75\% fibra de coco $+25 \%$ esterco bovino proporcionou aumento de matéria fresca da parte aérea quando comparado ao tratamento $100 \%$ pó de coco em mudas de couve-flor, concluindo ser a utilização unicamente de pó de coco desfavorável, resultados semelhantes aos encontrados neste trabalho.
A análise dos tratamentos T2 $(0,11)$, T3 $(0,09)$ e T4 $(0,08)$ atingiram os maiores resultados para matéria fresca do sistema radicular (Tabela 2), sendo o menor valor encontrado no tratamento T5 com $(0,05)$. Desse modo, os resultados demonstram que a elevação do esterco bovino curtido promoveu maior acúmulo de matéria verde do sistema radicular das plantas de tomateiro até certo ponto, sendo o seu excesso prejudicial e causando decréscimos dos níveis de fitomassa. A não utilização de esterco bovino curtido no tratamento $\mathrm{T} 1$, também provocou redução no acúmulo de fitomassa da cultura do tomateiro, uma vez que, o uso predominante do pó de coco sem a mistura a outros materiais como substrato agrícola se dá como meio inerte, assim, apresentando uma baixa concentração de nutrientes (Carvalho, 2009). No tratamento T5, o possível aumento da densidade do substrato quando acrescido o esterco bovino curtido em maiores quantidades provavelmente, impediu a máxima expressão e desenvolvimento da raiz, além de favorecer a elevação do acúmulo de sais e possível desequilíbrio nutricional provocado pela sua alta adição.

Steffen et al. (2010) relatam que a utilização do húmus de esterco bovino, embora tenha uma alta fertilidade, quando adicionada a casca de arroz carbonizada promoveu maior adensamento do substrato dificultando o crescimento das mudas de boca-de-leão.

Para o peso de massa seca da parte radicular (Tabela 2) obteve resultado significativo com destaque para os substratos T2 $(0,0103)$ e T3 $(0,0118)$, embora o tratamento $\mathrm{T} 2$, não tenha diferido estaticamente do tratamento T4 $(0,0085)$. Os menores resultados foram observados no tratamento T1 $(0,0070)$ e T5 $(0,0050)$. Costa et al. (2007) também observaram que o uso unicamente de pó de fibra de coco causou redução nos níveis de peso seco da raiz do tomateiro, enquanto que sua associação com resíduo de algodão compostado provocou o aumento de seus índices de matéria seca.

$\mathrm{O}$ resultado encontrado em $\mathrm{T} 5$ pode ser explicado pelo fato da densidade de alguns substratos afetarem negativamente o desenvolvimento do sistema radicular durante o período de avaliação (Quisen et al., 2013). Tal fato acontece, pois, embora a casca de coco torne o substrato menos denso, a utilização de esterco bovino como fonte de adubo orgânico promove um maior adensamento (Silva et al., 2009).

O substrato T4 obteve o maior resultado médio com 0,0978 diferindo estatisticamente de todos os tratamentos, que não diferiram estatisticamente entre si para à variável peso matéria seca da parte aérea (Tabela 3). Isso pode ter ocorrido pela maior disponibilidade de nutrientes 
em doses ideais para cultura do tomateiro em T4, o que favoreceu maior concentração de peso matéria seca da parte aérea para este tratamento. Uma vez que, segundo Brito e Mourão (2012), além da manutenção de características químicas como pH, capacidade de troca catiônica (CTC) e salinidade, a maior quantidade de nutrientes são fatores essenciais para qualidade de substratos.

Tabela 3 - Peso matéria seca da parte aérea (PMSPA) e Índice de Qualidade de Dickson (IQD) de mudas tomateiro variedade Santa Cruz Kada (Paulista) em combinações de substrato de pó de coco e esterco bovino curtido. Coronel João Sá- BA, 2018

\begin{tabular}{ccc}
\hline Tratamentos & PMSPA (g) & IQD \\
\hline T4 (70\%PC + 30\%EBC) & 0,0978 a & $0,0068 \mathrm{ab}$ \\
T3 (80\%PC + 20\%EBC) & $0,0780 \mathrm{~b}$ & $0,0085 \mathrm{a}$ \\
T2 (90\%PC + 10\%EBC) & $0,0733 \mathrm{~b}$ & $0,0068 \mathrm{ab}$ \\
T1 (100\%PC + 0\%EBC) & $0,0710 \mathrm{~b}$ & $0,0055 \mathrm{bc}$ \\
T5 (60\%PC + 40\%EBC) & $0,0683 \mathrm{~b}$ & $0,0038 \mathrm{c}$ \\
CV\% & 9,27 & 14,46 \\
\hline
\end{tabular}

*Médias seguidas de mesma letra, na coluna, não diferem entre si a 5\% da probabilidade pelo teste Tukey. $\mathrm{PC}=$ Pó de coco; $\mathrm{EBC}=$ Esterco bovino curtido.

O tratamento T1 pode ter sido prejudicado pela ausência de nutrientes, uma vez que, este tratamento não recebeu a adição de esterco bovino curtido. Conforme Cardoso e Ustulin Filho (2013), o substrato pó de coco é pobre em nutrientes para as plantas. Silva (2007), utilizando diferentes concentrações de compostos orgânicos e fibra de coco verde para produção de mudas na cultura da alface concluiu que a proporção $30 \%$ de fibra de coco verde + adubação orgânica, apresentaram maiores valores de massa seca da parte aérea. Assim, pode-se inferir que quantidades adequadas de pó de coco podem influenciar em características produtivas (qualitativas e quantitativas) de mudas no processo de produção das diferentes espécies existentes, influenciando-as de modo positivo e/ou negativo.

A análise da variável "índice de qualidade de Dickson” demonstrou que os substratos T2 $(0,0068)$, T3 $(0,0085)$ e T4 $(0,0068)$ obtiveram os maiores resultados, o tratamento T1 $(0,0055)$ apresentou menor IQD juntamente com o substrato T5 (0,0038). Este resultado pode ser relacionado ao fato do uso de pó de coco ter proporcionado boas características físicas ao substrato sendo as suas características nutricionais complementadas pelo esterco bovino curtido até os níveis de 30\%.

No entanto, a elevação da quantidade de esterco bovino curtido utilizado acima do nível de 30\% comprometeu as características físicas e químicas dos substratos, provocando sérios danos às mudas de tomateiro como se pode notar no tratamento T5 que obteve o menor índice de qualidade de mudas. De acordo com Diniz; Guimarães e Luz (2006), a porosidade é um fator muito importante para o pleno desenvolvimento das plantas, influenciando sobre a capacidade de retenção de água, aeração e drenagem adequada. Desta forma, os resultados presentes em T1 podem ser associados a uma maior densidade do substrato que pode restringir a disponibilidade de água, ar e nutrientes, prejudicando o crescimento radicular e da parte aérea de plantas (Feitosa et al., 2017).

Fonseca et al. (2002) afirmam que o índice de qualidade de Dickson pondera os resultados de diversos parâmetros importantes considerando a robustez e o equilíbrio da distribuição de biomassa da muda, sendo de grande auxílio para escolha de mudas com maior qualidade. Devendo o produtor optar por escolher à proporção que tenha uma maior viabilidade com base nos preços e disponibilidade dos materiais pó de coco e esterco bovino curtido presentes em sua região.

\section{CONCLUSÕES}

O tratamento $\mathrm{T} 1$ composto por $100 \%$ pó de coco $+0 \%$ de esterco bovino curtido proporciona maior comprimento do sistema radicular.

O excesso de esterco bovino curtido acima dos níveis de $30 \%$ provoca perdas produtivas no diâmetro do caule, matéria fresca do sistema radicular, peso matéria seca da parte radicular, peso matéria seca da parte aérea e índice de Qualidade de Dickson.

Os tratamentos nos quais foram adicionados 10 , 20 e $30 \%$ de esterco bovino curtido em substrato composto pela mistura de esterco bovino e pó de coco, promoveram maior qualidade de mudas.

\section{LITERATURA CITADA}

AGOSTINHO, A. L. Utilização de diferentes substratos na produção de mudas de manjericão. 2014. 35 f. Trabalho de Conclusão de Curso (Graduação em Engenharia 
Agronômica) - Universidade De Brasília - UnB, Faculdade de Agronomia e Medicina Veterinária - FAV, Brasília - DF, 2014.

ANDRADE, M. C. R.; SANTOS, J. M. A.; SILVA, P. M. R.; CAMPOS, N. M. Produção de tomate rasteiro por irrigação localizada. Revista Saberes UniAGES, Paripiranga-Bahia, v. 1, n. 5, p. 18-22, 2017.

BARBOSA, M. G.; DAVID, A. M. S. de S.; SARMENTO, H. G.; AMARO, H. T. R.; FIGUEIREDO, J. C.; NOBRE, D. A. C. Métodos alternativos de secagem e qualidade fisiológica de sementes de pimentão. Revista Científica Eletrônica de Agronomia, n. 28, dez. 2015. (Periódico Semestral).

BORGES, B. M. M. N.; LUCAS, F. T.; MODESTO, V. C.; PRADO, R DE. M.; SILVA, E. S da., BRAOS, B. B. Métodos de determinação da matéria seca e dos teores de macronutrientes em folhas de alface. Revista Trópica Ciências Agrárias e Biológicas, v. 5, n. 1, p. 12-16, abr. 2011.

BRITO JUNIOR, F. P. Produção de tomate (Solanum lycopersicum l.) reutilizando substratos sob cultivo protegido no município de Iranduba-AM. 2012. 61 f. Dissertação - (Mestrado em Agronomia Tropical), Universidade Federal do Amazonas, Faculdade de ciências agrárias, Manaus-AM, 2012.

BRITO, L. M.; MOURÃO, I. Características dos substratos para horticultura: Propriedades e características dos substratos (Parte I / II). AGROTEC - Revista TécnicoCientifica Agrícola, n. 2, dez. 2012.

CANELlA, D. S.; LOUZADA, M. L. C.; CLARO, R. M.; COSTA, J. C.; BANDONI, D. H.; LEVY, R. B.; MARTINS, A. P. B. Consumo de hortaliças e sua relação com os alimentos ultraprocessados no Brasil. Revista Saúde Pública, v.52, p.50, 2018.

CARDOSO, A. I. I.; USTULIN FILHO, A. J. Produção de chicória em função de doses de nitrogênio e potássio aplicadas na fase de mudas. Horticultura Brasileira, v. 31, n. 4, oct. 2013.

CARVALHO, J. M. M. (Org.). Apoio do BNB à pesquisa e desenvolvimento da fruticultura regional. Fortaleza: Banco do Nordeste do Brasil, p. 244, 2009. (Série BNB Ciência e Tecnologia, n. 4).

COELHO, R. G.; OLIVEIRA, F. D. F.; SOUZA, E. B.; AZEVEDO, J. M. A..; LIMA, M. O. Desenvolvimento e características produtivas de tomate do tipo cereja em diferentes compostos orgânicos. Revista ESPACIOS, v. 39, n. 26, nov. 2018.
COSTA, D. D. A. C.; BORGES, R. M.; MORAES, L. C; SILVA, S. S; MAZETTO JÚNIOR, J. C. Viabilidade de substratos alternativos na produção de mudas de tomateiro. Enciclopédia Biosfera, Centro Científico Conhecer, Goiânia, v.14, n.26, p.787, maio. 2017.

COSTA. L. M.; ANDRADE. J. W. de S.; ROCHA. A. C. da; SOUZA. L. de P.; FLÁVIO NETO. J. Avaliação de diferentes substratos para o cultivo de pepino. Global science and technology, v. 02, n. 02, p.21-26, mai/ago. 2009.

COSTA; C. A da.; RAMOS; S. J.; SAMPAIO; R. A.; GUILHERME; D. O.; FERNANDES, L. A. Fibra de coco e resíduo de algodão para substrato de mudas de tomateiro. Horticultura Brasileira, v. 25, n. 3, jun/set. 2007.

DANIEL, O.; VITORINO, A.C.T.; ALOVISI, A.A.; MAZZOCHIN, L.; TOKURA, A.M.; PINHEIRO, E.R.P.; SOUZA, E.F. Aplicação de fosforo em mudas de Acacia mangium willd. Revista Árvore, Viçosa, v.21, n.2, p.163168, 1997.

DEMONTIÊZO, F. L. L.; ARAGÃO, M. F.; JUNIOR, M. V.; MOREIRA, F. J. C.; PAIVA, P. V. V.; LIMA, S. C. R. V. Emergência e crescimento inicial de tomate 'santa clara' em função da salinidade e condições de preparo das sementes. Irriga, Botucatu, Edição Especial, IRRIGA \& INOVAGRI, p. 81-92, out. 2016.

DICKSON, A.; LEAF, A. L., HOSNER, J. F. Quality appraisal of white spruce and white pine seedling stock in nurserie. The Forestry Chronicle, v. 36, p. 10-13, 1960.

DINIZ, K. A.; GUIMARÃES, S. T. M. R.; LUZ, J. M. K. Húmus como substrato para a produção de mudas de tomate, pimentão e alface. Bioscience Journal, Uberlândia, v. 22, n. 3, p. 63-70, set./dez. 2006.

DUARTE, R. F.; REGYNALDO A.; SAMPAIO, R. A.; BRANDÃO JÚNIOR, D. S.; FERNANDES, L. A.; SILVA, H. P. Crescimento inicial de Acácia em condicionador formado de fibra de coco e resíduo agregante. Revista Brasileira de Engenharia Agrícola e Ambiental, Campina Grande, PB, UAEA/UFCG, v.14, n.11, p.1176-1185, out. 2010.

DUARTE, T. da. S.; PEIL, R. M. N. Relações fonte:dreno e crescimento vegetativo do meloeiro. Horticultura brasileira., v. 28, n. 3, p. 271-276, ago. 2010.

EICHOLZ, M. D., FONSECA, E. R., HARTER, A., EICHOLZ, E. D., SILVA, S. D. dos A. e. Qualidade física e fisiológica de sementes de Tungue (Aleurites Fordii Hemsl.). In: SIMPÓSIO ESTADUAL DE AGROENERGIA, IV REUNIÃO TÉCNICA DE AGROENERGIA, 2012, 
AMRIGS: Porto Alegre - RS. Anais... Pelotas: Embrapa Clima Temperado, 2012.

FAOSTAT - FOOD AND AGRICULTURE ORGANIZATION STATISTICAL DATABASE, 2017. Disponível em: <http://www.fao.org/faostat/es/\#data/QC > Acesso em: 11 jan. 2018.

FEITOSA, F. R. C.; GUIMARÃES, M. A.; HENDGES, A. R. A. A.; SILVA, B. N.; TAKANE, R. J. Efeitos de temperaturas, recipientes e substratos no desenvolvimento de Brassica rapa subsp. nipposinica. Revista de la facultad de agronomía (LA PLATA), v. 116, p. 39-50, maio. 2017.

FERREIRA, D. F. SISVAR: um programa para análises e ensino de estatística. Revista Científica Symposium, Lavras, v. 6, n. 2, p. 36-41, jul./dez. 2008.

FONSECA, E. P.; VALÉRI, S. V.; MIGLIORANZA, E.; FONSECA, N. A. N.; COUTO, L. Padrão de qualidade de mudas de Trema micrantha (L.) Blume, produzidas sob diferentes períodos de sombreamento. Revista Árvore, Viçosa, MG, v. 26, n. 4, p. 515-523, jun. 2002.

GIROTTO, K. T.; GIANINI, B. G.; VITORI, L. S.; FERNANDES JUNIOR, R. J.; GUALBERTO, R. Efeito da adição de cinzas e esterco ovino na fibra de coco na produção de mudas de couve-flor. In: $16^{\circ}$ CONGRESSO NACIONAL DE INICIAÇÃO CIENTÍFICA, faculdade ENIAC, Anais... CONIC-SEMESP, Guarulhos, 2016.

GOMES, J. M.; COUTO, L.; LEITE, H. G.; XAVIER, A.; GARCIA, S. L. R. Parâmetros morfológicos na avaliação da qualidade de mudas de Eucalyptus grandis. Revista Árvore, Sociedade de investigação florestais - SIF, ViçosaMG, v.26, n.6, p.655-664, 2002.

INSTITUTO BRASILEIRO DE GEOGRAFIA E ESTATÍSTICA - IBGE. Levantamento sistemático da produção agrícola: pesquisa mensal de previsão e acompanhamento das safras agrícolas no ano civil. Fundação Instituto Brasileiro de Geografia e Estatística IBGE, Rio de Janeiro, v.30, n.12, p.1-82, 2017.

LIN, L-j.; LUTHER, G. C.; HANSON, P. Raising healthy tomato seedlings. AVRDC - The World Vegetable Center, 15-795, 2015. 15 p.

NADAI, F. B.; MENEZES, J. B. de C.; CATÃO, H. C. R. M.; ADVÍNCULA, T.; COSTA, C. A. Produção de mudas de tomateiro em função de diferentes formas de propagação e substratos. RevistaAgro@mbiente On-line, v. 9, n. 3, p. 261-267, jul/set. 2015.

NUNES, M. U. C.; OLIVEIRA, H. J. C.; LIMA, I. S.; JESUS, A. F.; CRUZ, D. P.; SANTOS, L. S. Efeito de substratos formulados com resíduos agroindustriais no desenvolvimento de mudas de tomateiro. Horticultura
Brasileira, v. 30, n. 2, p. 5620-5626, jul. 2012. (Suplemento - CD Rom).

NUNES, M.U.C. Produção de mudas de hortaliças com o uso de plasticultura e pó de coco. Aracaju: Embrapa Tabuleiros Costeiros, n. 13, p. 29, 2000.

OLARIA, M.; NEBOT, J. F.; MOLINA, H.; TRONCHO, P.; LAPEÑA, L.; LLORENS, E. Effect of different substrates for organic agriculture in seedling development of traditional species of Solanaceae. Spanish Journal of Agricultural Research, Instituto Nacional de Investigación y Tecnología Agraria y Alimentaria (INIA), v.14, p.7, mar. 2016.

PACHECO, M. V.; MATOS, V. P.; FERREIRA, R. L. C.; FELICIANO, A. L. P.; PINTO, K. M. S. Efeito de temperaturas e substratos na germinação de sementes de Myracrodruon urundeuva Fr. All. (ANACARDIACEAE). Revista Árvore, Viçosa-MG, v.30, n.3, p.359-367, 2006.

PEZZUTTI, R. P.; CALDATO, S. L. Sobrevivência e crescimento inicial de mudas de pinus taeda l. com diferentes diâmetros do colo. Ciência Florestal, Santa Maria, v. 21, n. 2, p. 355-362, abr/jun. 2011.

PRAGANA, R. B. Potencial do resíduo da extração da fibra de coco como substrato na produção agrícola. 1999. 88f. Dissertação (Mestrado em Agronomia) - Universidade Federal Rural de Pernambuco, Recife, 1999.

QUISEN, R. C.; RAIZER, M. D. M.; IRIARTE-MARTEL, J. H. Acclimatization of micropropagated plantlets of Heliconia Sexy Pink. Revista de Ciências Agrária, Amazonian Journal of Agricultural and Environmental Sciences, v. 56, n. Supl., p. 1-5, dez. 2013.

RAMOS, A. R. P.; DIAS, R, de C. S.; ARAGÃO CA.; MENDES, A. M. S. 2012. Mudas de melancia produzidas com substrato à base de pó de coco e soluções nutritivas. Horticultura Brasileira, v. 30, n. 2, p. 339-344, abr/jun. 2012.

RISTOW, N. C.; CARPENEDO, S.; ANTUNES, L. E. C. Enraizamento de microestacas de mirtileiro em diferentes substratos. Comunicado Técnico 249, Pelotas, RS, p. 1-8, 2010.

RODRIGUES, A. A. de J.; SANTOS, E. de O.; TORRES, R. de A.; LIMA, L. F. de.; TAKANE, R. J. Avaliação de substratos alternativos na germinação de sementes de manjericão (Ocimum basilicum L.). Cadernos de Agroecologia, Resumos do VIII Congresso Brasileiro de Agroecologia, Porto Alegre, RS, v. 8, n. 2, nov. 2013.

SÁ JÚNIOR, A. Aplicação da classificação climática de Köppen para o zoneamento climático de Minas gerais. 2009. 101 f. Dissertação (Mestrado em Engenharia 
Agrícola) - Universidade Federal de Lavras, Minas Gerais, 2009.

SANTOS, A. C. M.; CARNEIRO, J. S. S.; JUNIOR, J. M. F.; SILVA, M. C. A.; SILVA, R. Produção de mudas de tomateiro cv. Drica sob substratos alternativos. Agropecuária Científica no Semiárido - ACSA, v.11, n.4, p.01-12, 2015.

SANTOS, M. R.; SEDIYAMA, M. A. N.; SALGADO, L. T.; VIDIGAL, S. M.; REIGADO, F. R. Produção de mudas de pimentão em substratos à base de vermicomposto. Bioscience Journal., Uberlândia, v. 26, n. 4, p. 572-578, jul/ago. 2010.

SANTOS, S. T.; OLIVEIRA, F. A. O.; COSTA, J. P. B. M.; SOUZA NETA, M. L.; ALVES, R. C.; COSTA, L. P. Qualidade de mudas de cultivares de tomateiro em função de soluções nutritivas de concentrações crescentes. Revista Agro@mbiente On-line, v. 10, n. 4, p. 326-333, out/dez. 2016.

SILVA, J. E.; RESCK, D. V. Matéria Orgânica do solo: In: VARGAS, M. A. T.; HUNGRIA, M. (ed.). Biologia dos solos do Cerrado. Planaltina: Embrapa, CPAC, 1997, p. 467-524.

SILVA, L. G. Utilização agroecológica de fibra de coco (coccus nucifera L.) verde para melhoria da produção de alface (Lactuca sativa L.) cv. Rafaela. 2007. $64 \mathrm{f}$ Dissertação (Mestrado em agroecologia) - Universidade Estadual do Maranhão (UEMA), São Luís, MA, 2007.

SILVA, L. J. B.; CAVALCANTE, A. S. S.; ARAÚJO NETO, S. E. Produção de mudas de rúcula em bandejas com substratos a base de resíduos orgânicos. Ciências agrotécnicas, Lavras, v. 33, n. 5, p. 1301-1306, fev. 2009.

SILVA, P. S. S.; SANTOS, A. C. M.; FARIA, A. J. G.; LEITE, R. C.; FERREIRA JÚNIOR, J. M.; SILVA, R. R. Produção de mudas de tomate cV. Drica sob diferentes substratos alternativos. Amazon Soil - I Encontro de Ciência do Solo da Amazônia Oriental. Sociedade Brasileira de Ciência do Solo, Núcleo Regional Amazônia Oriental, Anais... Trabalhos completos, Gurupi, TO, p. 179185, 2014.

SILVA, R. R.; RODRIGUES, L. U.; FREITAS, G. A.; MELO, A. V.; NASCIMENTO, I. R.; ANDRÉA, A. F. D. Influência de casca de arroz carbonizada em diferentes substratos na qualidade de mudas de tomateiro. Revista Brasileira de Ciências Agrárias. Recife, PE, UFRPE, v.7, p.803-809, ago. 2012. (suplemento).

SILVA, R. R.; SANTOS, A. C. M.; FARIA, A. J. G.; RODRIGUES, L. U.; ALEXANDRINO, G. C.; NUNES, B. H. D. N. Substratos alternativos na produção de mudas de pimentão. Journal of Bioenrgy and Food Science., v.5, n.1, p.12-21, 2018.

SILVEIRA, E.B.; RODRIGUES, V.J.L.B.; GOMES, A.M.A.; MARIANO, R.L.R; MESQUITA, J.C.P. Pó de coco como substrato para produção de mudas de tomateiro. Horticultura Brasileira, Brasília, v. 20, n. 2, p. 211-216, jun. 2.002.

SOUZA. J. L.; BARRELLA. T. P.; SIQUEIRA. R. G.; SANTOS. R. H. S.; VIDAL. M. C. Propagação de Plantas. In: HENZ. G. P.; ALCÂNTARA. F. A.; RESENDE. F. V. Produção orgânica de hortaliças: o produtor pergunta, a Embrapa responde. Brasília, DF: Embrapa Informação Tecnológica, 2007. p. 308. (Coleção 500 perguntas, 500 respostas).

SPIASSI, A.; RUBIO, F.; KOELLN, F. T. S.; BENATTOJUNIOR, J. C.; COSTA, L. A. M.; MENDONÇA, M. S. S.; PAZ; J. C. S. Desenvolvimento de mudas de beterraba em diferentes substratos orgânicos. In: Anais... VI Congresso Brasileiro de Agroecologia. II Congresso Latino Americano de Agrecologia. Curitibá, PR, Brasil, 09 a 12 de novembro de 2009.

STEFFEN, G. P. K.; ANTONIOLLI, Z. I.; STEFFEN, R. B.; BELLÉ, R. Húmus de esterco bovino e casca de arroz carbonizada como substratos para a produção de mudas de boca-de-leão. Acta Zoológica Mexicana, (n.s.) Número Especial 2, p. 345-357, jan. 2010.

TRANI, P. E.; KARIYA, E. A.; HANAI, S. M.; ANBO, R. H.; BASSETTO JÚNIOR, O. B.; PURQUERIO, L. F. V.; TRANI, A. L. Calagem e adubação do tomate de mesa. Campinas: Instituto Agronômico. 2015. 35 p. online. (Série Tecnologia Apta. Boletim Técnico IAC, 215).

VERSLUES, P. E.; AGARWAL, M.; KATIYARAGARWAL, S.; ZHU, J.; ZHU, J-K. Methods and concepts in quantifying resistance to drought, salt and freezing abiotic stresses that affect plant water status. The Plant Journal, v. 45, p. 523-539, aug./sept. 2006.

Recebido para publicação em 15/07/2019 e aprovado em 21/09/2019. 